\title{
PENINGKATAN PRODUKTIVITAS PADI HIBRIDA MELALUI PEMBERIAN PUPUK N DENGAN SISTEM RATUN DI LAHAN RAWA PASANG SURUT
}

\section{ENHANCEMENT HYBRID RICE PRODUCTIVITY THROUGH APPLICATION N FERTILIZER WITH A RATUN SYSTEM IN TIDAL SWAMPLAND}

\author{
Gribaldi*, Nurlaili, dan Ekawati Danial \\ Program Studi Agroteknologi Fakultas Pertanian Universitas Baturaja, \\ Jl. Ratu Penghulu No. 02301 Karang Sari Baturaja 32115, Sumatera Selatan, Indonesia. \\ ${ }^{*}$ Tel/Faks +628127133718/(0735) 321822 \\ Email: gribaldi64@yahoo.co.id
}

\section{ABSTRACT}

The study aimed to determine the increase in productivity of hybrid paddy with a ratoon system at several doses and application of $N$ fertilizer on swamp land. The study was conducted in April - August 2019 in the Banyuasin District Agricultural Service Experimental Field, using a Factorial Randomized Block Design which was repeated three times. The factors studied consisted of; Treatment dose offertilizer (N): dose of $90 \mathrm{~kg} \mathrm{~N} / \mathrm{ha}$ (N1), dose $135 \mathrm{~kg} \mathrm{~N} / \mathrm{ha}$ (N2). Treatment application of fertilizer (A): application of $1 / 2$ dose fertilizer at planting $+1 / 2$ dose phase primordia (A1); fertilizer application 1/3 dose at planting + $1 / 3$ dose phase primordia $+1 / 3$ dose at harvest (A2), fertilizer application $1 / 3$ dose at planting $+1 / 3$ dose phase primordia $+1 / 6$ dose at harvest $+1 / 6$ doses 21 days after harvest (A3). The results showed that the dosage and application of $N$ fertilizer affected the increase in productivity of main and hybrid hybrid rice in swamp land, increased productivity of hybrid rice at several doses and the application of $N$ fertilizer ranged from 37.3 to $63.2 \%$. The highest productivity increase was obtained in the treatment of fertilizer dose $135 \mathrm{kgN} / \mathrm{ha}$ and its application 1/3 dose at planting $+1 / 3$ dose at primordia and 1/3 dose at harvest, which was $63.2 \%$ or grain yield of 7.28 tons $/ \mathrm{Ha}$

Keywords: dosage, fertilizer application, productivity, swamp land

\begin{abstract}
ABSTRAK
Penelitian bertujuan untuk mengetahui peningkatan produktivitas padi hibrida dengan sistem ratun pada beberapa dosis dan aplikasi pupuk $\mathrm{N}$ di Lahan rawa pasang surut. Penelitian dilaksanakan pada bulan April - Agustus 2019 di Lahan Percobaan Dinas Pertanian Kabupaten Banyuasin, dengan menggunakan Rancangan Acak Kelompok Faktorial (RAKF) yang diulang tiga kali. Faktor faktor yang diteliti terdiri dari; Perlakuan dosis pupuk (N): dosis $90 \mathrm{~kg} \mathrm{~N} / \mathrm{ha}(\mathrm{N} 1)$, dosis $135 \mathrm{~kg} \mathrm{~N} / \mathrm{ha}(\mathrm{N} 2)$. Perlakuan aplikasi pupuk (A): aplikasi pupuk 1/2 dosis saat tanam $+1 / 2$ dosis fase primordia (A1); aplikasi pupuk $1 / 3$ dosis saat tanam $+1 / 3$ dosis fase primordia $+1 / 3$ dosis saat panen (A2), aplikasi pupuk $1 / 3$ dosis saat tanam $+1 / 3$ dosis fase primordia $+1 / 6$ dosis saat panen $+1 / 6$ dosis pada 21 hari setelah panen (A3). Hasil penelitian menunjukan, dosis dan aplikasi pupuk $\mathrm{N}$
\end{abstract}


berpengaruh terhadap peningkatan produktivitas padi hibrida tanaman utama dan ratun di lahan rawa pasang surut, Peningkatan produktivitas padi hibrida pada beberapa dosis dan aplikasi pupuk $\mathrm{N}$ berkisar 37.3-63.2 persen. Peningkatan produktivitas tertinggi didapat pada perlakuan pemupukan dosis $135 \mathrm{kgN} / \mathrm{ha}$ dan aplikasinya $1 / 3$ dosis saat tanam $+1 / 3$ dosis saat primordia dan $1 / 3$ dosis saat panen, yaitu sebesar 63,2 persen atau dengan hasil gabah sebesar 7,28 ton/ha.

Kata kunci : Aplikasi pupuk, Dosis, Lahan Pasang Surut, Padi Hiva 5 Ceva, Produktivitas.

\section{PENDAHULUAN}

Peningkatan produksi dapat dilakukan dengan perbaikan produktivitas terutama pada lahan-lahan suboptimal, seperti lahan rawa pasang surut. Produksi padi di Lahan rawa pasang surut hingga saat ini masih rendah. Rendahnya produktivitas padi ini disebabkan antara lain oleh kondisi lingkungan terutama kondisi biofisik lahan (BBSDLP, 2011). Selanjutnya menurut Sudana, W. (2005); Naning. et al.(2008) dan Dakhyar, et al.(2012), pH tanah dan kesuburan tanah yang rendah menyebakan produktivitas padi rendah di lahan rawa pasang surut. Untuk itu diperlukan upaya peningkatan produktivitas padi ratun melalui pemberian pupuk terutama pupuk Nitrogen pada tanaman utama.

Menurut Triadiati et al. (2012), pupuk merupakan salah satu faktor utama pada usaha tani padi. Pemberian dosis pupuk juga tergantung pada varietas yang digunakan dan unsur Nitrogen yang terdapat pada pupuk merupakan salah satu unsur hara yang penting dan harus tersedia bagi tanaman (Ambarita et al., 2018). Nitrogen (N) merupakan unsur hara esensial dimana kebutuhan tanaman akan $\mathrm{N}$ lebih tinggi dibanding unsur lainnya, selain itu $\mathrm{N}$ merupakan faktor pembatas bagi produktivitas tanaman (Duan et al., 2007). Lebih lanjut Menurut Modhej et al.,(2008), menyatakan bahwa, pemupukan nitrogen memberi pengaruh yang signifikan terhadap peningkatan produksi tanaman padi.

Hasil penelitian Fifi (2016) menyatakan bahwa, penggunaan pupuk nitrogen dengan dosis $138 \mathrm{~kg} / \mathrm{ha}$ atau setara dengan $300 \mathrm{~kg}$ Urea/ha memberikan hasil tertinggi terhadap pertumbuhan dan hasil ratun. Sedangkan menurut Ambarita et al. (2018), dosis anjuran pupuk $\mathrm{N}$ untuk tanaman padi sebesar $92 \mathrm{~kg} /$ ha atau setara $200 \mathrm{~kg} \mathrm{Urea} / \mathrm{ha}$. Selanjutnya menurut Nurmayulis et al. (2011), pemberian pupuk Urea sebanyak $200 \mathrm{~kg} / \mathrm{ha}$ atau setara dengan $92 \mathrm{~kg} \mathrm{~N}$ mampu meningkatkan tinggi tanaman, jumlah anakan, dan produksi tanaman padi. Selain dosis, waktu aplikasi pupuk juga menentukan produktivitas padi.

Menurut Susilawati et al. (2010), pertumbuhan ratun sangat tergantung pada komposisi, waktu pemupukan dan tingkat dosis pupuk yang diberikan pada tanaman utama dan tanaman ratun, terutama pupukN. Selanjutnya Menurut Alfandi (2006), aplikasi pupuk $\mathrm{N}$ setengah dosis pada saat tanam akan mempengaruhi pertumbuhan fase vegetatif tanaman, terutama tinggi tanaman dan pembentukan anakan. Sedangkan hasil penelitian Gribaldi et al. (2013) menunjukkan pemupukan separuh dosis Urea pada 
saat tanam + Si dan Zn, dimana sisanya diberikan 42 hst memberikan hasil gabah tertinggi pada semua varietas yang diuji untuk kondisi cekaman rendaman 7-14 hst.

Penelitian ini bertujuan untuk mengetahui peningkatan produktivitas padi hibrida dengan sistem ratun pada beberapa dosis dan aplikasi pupuk $\mathrm{N}$ di Lahan pasang surut.

\section{BAHAN DAN METODE}

Penelitian ini dilaksanakan mulai bulan April sampai Agustus 2019 di Lahan Percobaan Dinas Pertanian Kabupaten Banyuasin, Desa Telang Sari Kecamatan Tanjung Lago Kabupaten Banyuasin, dengan menggunakan Rancangan Acak Kelompok Faktorial (RAKF) yang diulang sebanyak tiga kali. Faktor faktor yang diteliti terdiri dari; Perlakuan dosis pupuk $\mathrm{N}(\mathrm{N})$, yaitu dosis $90 \mathrm{~kg} \mathrm{~N} / \mathrm{ha}(\mathrm{N} 1)$, dosis 135 $\mathrm{kg} \mathrm{N} / \mathrm{ha}(\mathrm{N} 2)$, Perlakuan aplikasi pupuk nitrogen (A), yaitu aplikasi pupuk $1 / 2$ dosis saat tanam $+1 / 2$ dosis fase primordia (A1); aplikasi pupuk 1/3 dosis saat tanam $+1 / 3$ dosis fase primordia $+1 / 3$ dosis saat panen (A2), aplikasi pupuk 1/3 dosis saat tanam + 1/ 3 dosis fase primordia $+1 / 6$ dosis saat panen $+1 / 6$ dosis pada 21 hari setelah panen (A3).

Benih padi hibrida yang digunakan varietas Hipa 5 Ceva diinkubasi selama 3 hari, setelah berkecambah disemaikan pada bedengan yang berukuran 1,2 $\mathrm{m} \times 8 \mathrm{~m}$. Bibit yang telah berumur 21 hari dipindahkan ke setiap petak (unit) percobaan, yang berukuran $3 \mathrm{~m} \times 2 \mathrm{~m}$ dimana sebelumnya diberi pupuk kandang dengan takaran 10 ton $\mathrm{ha}^{-1}$, selanjutnya bibit ditanam dengan posisi tegak dengan jarak tanam 25 $\mathrm{cm} \times 25 \mathrm{~cm}$, dan menggunakan 2 bibit per lubang yang kedalamannya cukup $2 \mathrm{~cm}$, metode ini mengikuti metode (Gribaldi et al., 2016). Pemupukan P dan K diberikan pada saat tanam untuk semua perlakuan, dengan dosis untuk satu hektar masing-masing $60 \mathrm{~kg}$ (Setiawan et al., 2012), sedangan dosis dan aplikasi pupuk N disesuaikan dengan perlakuan. Selain itu padi ratun untuk semua perlakuan diberi zat pengatur tumbuh (ZPT) sebanyak 60 ppm GA3 yang disemprotkan 7 hari sekali (Warso, 2014). Penyemprotan ZPT dimulai 3 hari setelah pemotongan batang utama sampai menjelang panen. Pemotongan batang tanaman utama pada saat panen dilakukan dengan ketinggian 15-20 cm dari permukaan tanah, metode ini mengikuti metode (Nakano et al., 2009).

Pengamatan karakter agronomi, baik pada tanaman utama maupun ratun meliputi: Jumlah anakan produktif per rumpun (anakan), Bobot 1000 butir gabah (g), Jumlah gabah per malai (butir), Persentase gabah hampah per malai (\%) dan Hasil gabah yang dikonversikan dalam hektar (ton)

Analisis Data. Data karakter agronomi dianalisis secara statistic menggunakan Analysis of Variance (ANOVA) yang dilanjutkan dengan uji Beda Nyata Jujur (BNJ) pada taraf nyata 5\%. Semua perhitungan data akan dibantu dengan program SPSS 22.0, serta data ditampilkan dalam bentuk tabel dan gambar. 


\section{HASIL DAN PEMBAHASAN}

Berdasarkan hasil analisis sifat kimia tanah sebelum perlakuan, lahan percobaan yang digunakan menunjukkan tingkat kesuburan tanah sangat rendah, $\mathrm{pH}$ tanah tergolong masam $(\mathrm{pH} 4,63)$ dengan kandungan Al-dd tinggi (Tabel 1.). Kandungan basa seperti $\mathrm{Ca}, \mathrm{Mg}$ dan $\mathrm{K}$-dd tergolong sangat rendah sampai rendah yang mengindikasikan rendahnya ketersediaan hara. Untuk itu diperlukan peningkatan kesuburan tanah dengan melakukan pemberian pupuk kandang 10 ton/ha dan Nitrogen pada tanaman utama, sehingga diharapkan dapat mengatasi kekurangan ketersediaan unsur hara dan dapat meningkatkan produktivitas padi.

Tabel 1. Hasil analisis beberapa sifat tanah sebelum perlakuan

\begin{tabular}{lcc}
\hline \multicolumn{1}{c}{ Jenis Analisis } & Nilai & *Kriteria \\
\hline $\mathrm{pH} \mathrm{H} \mathrm{H}_{2} \mathrm{O}$ & 4,63 & Masam \\
$\mathrm{C}-$ Organik $(\%)$ & 3,29 & Tinggi \\
$\mathrm{N}-$ total $(\%)$ & 0,25 & Sedang \\
$\mathrm{P}-$ Bray $1(\mathrm{ppm})$ & 27 & Tinggi \\
$\mathrm{K}-\mathrm{dd}(\mathrm{cmol}(+) / \mathrm{kg})$ & 0,13 & Rendah \\
$\mathrm{Na}(\mathrm{cmol}(+) / \mathrm{kg})$ & 0,33 & Rendah \\
$\mathrm{Ca}(\mathrm{cmol}(+) / \mathrm{kg})$ & 0,70 & Rendah \\
$\mathrm{Mg}(\mathrm{cmol}(+) / \mathrm{kg})$ & 0,22 & Sangat Rendah \\
$\mathrm{KTK}(\mathrm{cmol}(+) / \mathrm{kg})$ & 15,23 & Rendah \\
$\mathrm{Al}-\mathrm{dd}(\mathrm{cmol}(+) / \mathrm{kg})$ & 2,10 & Tinggi \\
Tekstur & & \\
$\quad$ Pasir $(\%)$ & 41,94 & \\
Debu $(\%)$ & 24,08 & \\
Liat $(\%)$ & 33,98 & \\
\hline
\end{tabular}

Sumber: Laboratorium Ilmu Tanah Fakultas Pertanian Unsri, Sumatera Selatan. 2019.

*Kriteria berdasarkan Balai Penelitian Tanah (2005).

Tabel 2. Hasil analisis keragaman pengaruh dosis dan aplikasi pupuk N padi hibrida varietas Hipa 5 ceva terhadap peubah yang diamati.

\begin{tabular}{|c|c|c|c|c|c|c|c|}
\hline \multirow{3}{*}{ No } & \multirow{3}{*}{ Peubah yang diamati } & \multirow{2}{*}{\multicolumn{2}{|c|}{$\frac{\text { Dosis N }}{(\mathrm{N})}$}} & \multirow{2}{*}{\multicolumn{2}{|c|}{ Aplikasi pupuk (A) }} & \multirow{2}{*}{\multicolumn{2}{|c|}{$\begin{array}{c}\text { Interaksi } \\
\text { (I) }\end{array}$}} \\
\hline & & & & & & & \\
\hline & & TU & $\mathrm{R}$ & TU & $\mathrm{R}$ & TU & $\mathrm{R}$ \\
\hline 1 & Jumlah anakan produktif (anakan) & $3.48 \mathrm{~ns}$ & $0.01 \mathrm{~ns}$ & $0.27 \mathrm{~ns}$ & $1.59 \mathrm{~ns}$ & $0.24 \mathrm{~ns}$ & $0.14 \mathrm{~ns}$ \\
\hline 2 & Bobot 1000 butir gabah (g) & $4.32 \mathrm{~ns}$ & $2.03 \mathrm{~ns}$ & $0.96 \mathrm{~ns}$ & $0.53 \mathrm{~ns}$ & $0.33 \mathrm{~ns}$ & $0.29 \mathrm{~ns}$ \\
\hline 3 & Jumlah gabah per malai (butir) & $0.56 \mathrm{~ns}$ & $0.01 \mathrm{~ns}$ & $11.12 *$ & $0.16 \mathrm{~ns}$ & $0.77 \mathrm{~ns}$ & $0.80 \mathrm{~ns}$ \\
\hline 4 & Persentase gabah hampah (\%) & $1.62 \mathrm{~ns}$ & $0.88 \mathrm{~ns}$ & $2.27 \mathrm{~ns}$ & $0.30 \mathrm{~ns}$ & $0.26 \mathrm{~ns}$ & $5.03 *$ \\
\hline 5 & Hasil gabah per hektar (ton) & $0.43 \mathrm{~ns}$ & $1.07 \mathrm{~ns}$ & $0.35 \mathrm{~ns}$ & $1.33 \mathrm{~ns}$ & $0.28 \mathrm{~ns}$ & $1.08 \mathrm{~ns}$ \\
\hline
\end{tabular}

Keterangan: $\quad *$ =berpengaruh nyata; $\mathrm{s}=$ berpengaruh tidak nyata; $\mathrm{TU}=$ tanaman utama

$$
\mathrm{R} \text { = ratun }
$$


Tabel 3. Komponen hasil tanaman utama dan ratun padi hibrida varietas Hipa 5 Ceva melalui perlakua dosis dan aplikasi pupuk $\mathrm{N}$ di Lahan pasang surut.

\begin{tabular}{ccccc}
\hline \multirow{2}{*}{ Perlakuan } & \multicolumn{2}{c}{ Jml Anakan Produktif(anakan) } & \multicolumn{2}{c}{ Bobot 1000 butir gabah $(\mathrm{g})$} \\
\cline { 2 - 5 } N1A1 & $\mathrm{TU}$ & $\mathrm{R}$ & $\mathrm{TU}$ & $\mathrm{R}$ \\
N1A2 & 9 & 6.3 & 25.1 & 22.3 \\
N1A3 & 9.6 & 5.8 & 23.7 & 22.8 \\
N2A1 & 7.9 & 5.3 & 26.5 & 22.5 \\
N2A2 & 11.2 & 6.7 & 25 & 19.9 \\
N2A3 & 10.6 & 5.8 & 23 & 21.7 \\
Perlakuan & 10.7 & 4.8 & 25.1 & $\mathrm{R}$ \\
\cline { 2 - 5 } N1A1 & Jumlah gabah per malai & PU & $35.0 \mathrm{bc}$ \\
N1A2 & TU & $\mathrm{R}$ & $8.5 \mathrm{a}$ \\
N1A3 & 116 & 40.6 & 6.4 & 20.5 \\
N2A1 & 99 & 43.5 & 6.8 & $\mathrm{a}$ \\
N2A2 & 92.7 & 44 & 7.7 & $43.6 \mathrm{c}$ \\
N2A3 & 125.3 & 45 & 4.3 & $20.2 \mathrm{a}$ \\
\hline
\end{tabular}

Keterangan: Angka yang diikuti huruf yang sama pada kolom yang sama menunjukkan tidak berbeda nyata berdasarkan uji BNT pada taraf 5\%. N1: dosis $90 \mathrm{~kg} \mathrm{~N} / \mathrm{ha}, \mathrm{N} 2$ : dosis $135 \mathrm{~kg} \mathrm{~N} / \mathrm{ha}$, A1: Aplikasi pupuk 1/2 dosis saat tanam $+1 / 2$ dosis fase primordia, A2: Aplikasi pupuk 1/3 dosis saat tanam $+1 / 3$ dosis fase primordia $+1 / 3$ dosis saat panen, A3: Aplikasi pupuk $1 / 3$ dosis saat tanam $+1 / 3$ dosis fase primordia $+1 / 6$ dosis saat panen $+1 / 6$ dosis pada 21 hari setelah panen (A3). TU: Tanaman Utama, R: Ratun

Hasil analisis keragaman pada Tabel 2 menunjukkan bahwa untuk setiap peubah antar Dosis $\mathrm{N}$ berpengaruh tidak nyata pada semua peubah yang diamati, sedangkan untuk setiap peubah antarAplikasi pupuk berpengaruh tidak nyata kecuali pada peubah, jumlah gabah permalai pada tanaman utama. Interaksi antar Dosis N dan aplikasi pupuk berpengaruh tidak nyata kecuali pada peubah, persentase gabah hampa per malai pada ratun.

Hasil analisis keragaman perlakuan dosis dan aplikasi pupuk $\mathrm{N}$ berpengaruh tidak nyata terhadap produktivitas padi, baik pada tanaman utama maupun ratun untuk semua perlakuan (Tabel4), namun secara tabulasi perlakuan dosis dan aplikasi pupuk $\mathrm{N}$ menunjukan adanya peningkatan produktivitas sebesar 37.3 - 63.2 persen. Perlakuan pemberian pupuk Nitogen dengan dosis $135 \mathrm{~kg} /$ ha yang diberikan $1 / 3$ dosis pada saat tanam $+1 / 3$ dosis pada saat primodia $+1 / 3$ dosis diberikan pada saat panen cenderung menghasilkan total produksi (TU+R) lebih tinggi dibanding perlakuan lainnya, dengan hasil gabah yaitu 7.28 ton/ha atau mengalami peningkatan produktivitas sebesar 63.2 persen. Tingginya hasil padi yang diperoleh pada perlakuan ini diduga ketersediaan hara yang cukup bagi tanaman utama dan ratun untuk menghasilkan asimilat sehingga ketersediaan asimilat yang tinggi dapat meningkatkan hasil gabah baik pada 
Tabel 4. Hasil tanaman utama dan ratun padi hibrida varietas Hipa 5 Ceva melalui perlakuan dosis dan aplikasi pupuk $\mathrm{N}$ di Lahan pasang surut.

\begin{tabular}{ccccc}
\hline \multirow{2}{*}{ Perlakuan } & \multicolumn{3}{c}{ Hasil gabah (ton/ha) } & \multirow{2}{*}{ \% R/TU } \\
\cline { 2 - 4 } & TU & R & TU+R & 58.5 \\
N1A1 & 4.1 & 2.4 & 6.5 & 58.2 \\
N1A2 & 4.33 & 2.52 & 6.85 & 61.8 \\
N1A3 & 4.04 & 2.5 & 5.96 & 37.3 \\
N2A1 & 4.9 & 1.83 & 6.73 & 63.2 \\
N2A2 & 4.46 & 2.82 & 7.28 & 43.7 \\
N2A3 & 4.03 & 1.95 & 5.98 & \\
\hline
\end{tabular}

Keterangan: Angka yang diikuti huruf yang sama pada kolom yang sama menunjukkan tidak berbeda nyata berdasarkan uji BNT pada taraf 5\%. N1: dosis $90 \mathrm{~kg} \mathrm{~N} / \mathrm{ha}, \mathrm{N} 2$ : dosis $135 \mathrm{~kg} \mathrm{~N} / \mathrm{ha}, \mathrm{A} 1$ : Aplikasi pupuk 1/2 dosis saat tanam $+1 / 2$ dosis fase primordia, A2: Aplikasi pupuk $1 / 3$ dosis saat tanam $+1 / 3$ dosis fase primordia $+1 / 3$ dosis saat panen, A3: Aplikasi pupuk $1 / 3$ dosis saat tanam $+1 / 3$ dosis fase primordia $+1 / 6$ dosis saat panen $+1 / 6$ dosis pada 21 hari setelah panen (A3). TU: Tanaman Utama, R: Ratun

tanaman utama maupun ratun. Menurut Petroudi et al. (2011) kemampuan tanaman menghasilkan ratun salah satunya ditentukan oleh pemupukan. Selanjutnya Menurut Siregar dan Marzuki (2011), efisiensi pemupukan terutama pupuk Nitrogen dapat dilakukan melalui pengaturan pemupukan, yaitu pemberian pupuk disesuaikan dengan tahapan perkembangan tanaman padi. Selain itu menurut Susilawati et al. (2010), tingkat dosis pupuk yang diberikan pada tanaman utama dan tanaman ratun, terutama pupuk $\mathrm{N}$ sangat berpengaruh terhadap pertumbuhan ratun. Sedangkan menurut Bovairi et al. (2016) bahwa peningkatan hasil dan komponen hasil disebabkan meningkatnya transfer asimilat kedalam biji. Secara tabulasi produksi ratun pada perlakuan N2A1 cenderung lebih rendah dibanding dengan perlakuan lainnya, hal ini disebabkan perlakuan N2A1 memiliki persentase gabah hampah lebih tinggi dibanding perlakuan lainnya, yaitu sebesar 43,6 persen (Tabel 3) .

Hasil uji BNT taraf 5 persen pada peubah persentase gabah hampa pada ratun menunjukkan bahwa perlakuan N1A1 berbeda tidak nyata dengan N2A1 dan N2A3, namun berbeda nyata dengan N1A2 dan N2A2. Perlakuan pemberian pupuk $\mathrm{N}$ dosis $135 \mathrm{~kg} /$ ha yang diaplikasikan $1 / 3$ dosis pada saat tanam $+1 / 3$ dosis pada saat primodia $+1 / 3$ dosis di berikan pada saat panen (N2A2), menghasilkan persentase gabah hampa terendah baik pada tanaman utama (TU) maupun ratun $(R)$, yaitu masing-masing sebesar 4.3 dan 20.2 persen (Tabel 3). Hal ini diduga tanaman utama maupun ratun menghasilkan asimilat yang tinggi sehingga proses transfer asimilat ke biji meningkat untuk mengisi semua biji yang ada. Menurut Susilawati et al. (2010), tingginya persen gabah hampa yang terjadi diduga berkaitan dengan jumlah asimilat yang tidak cukup untuk mengisi semua gabah.

Pada penelitian ini perlakuan dosis dan aplikasi pupuk $\mathrm{N}$ menghasilkan tanaman utama dengan jumlah gabah yang cukup tinggi (N1A1 dan N2A1), ternyata 
memiliki persentase gabah yang tinggi pada tanaman utama dan ratun (Tabel 3.) Hal tersebut mengindikasikan bahwa faktor pembatas produktivitas padi dengan sistem ratun salah satunya dipengaruhi oleh tingginya persentase gabah hampa $(\mathrm{r}=0.61 *)$.

\section{KESIMPULAN}

Hasil penelitian menunjukkan bahwa dosis dan aplikasi pupuk $\mathrm{N}$ berpengaruh terhadap peningkatan produktivitas padi hibrida tanaman utama dan ratun di lahan rawa pasang surut, Peningkatan produktivitas padi hibrida pada beberapa dosis dan aplikasi pupuk $\mathrm{N}$ berkisar 37.3-63.2 persen. Peningkatan produktivitas tertinggi didapat pada perlakuan pemupukan dosis $135 \mathrm{kgN} / \mathrm{ha}$ dan aplikasinya $1 / 3$ dosis saat tanam $+1 / 3$ dosis saat primordia dan $1 / 3$ dosis saat panen, yaitu sebesar 63,2 persen atau dengan hasil gabah sebesar 7,28 ton/ha.

\section{UCAPAN TERIMA KASIH}

Terima kasih disampaikan kepada Kementerian Riset, Teknologi dan Pendidikan Tinggi yang telah membiayai penelitian ini melalui Hibah Kompetitif Nasional tahun 2019 dengan nomor kontrak: T/140/E3/RA.00/2019.

\section{DAFTAR PUSTAKA}

Alfandi. 2006. Pengaruh Tinggi Pemangkasan (Ratoon) dan Pupuk N terhadap Produksi Padi (Oryza sativa L.) Kultivar Ciherang.J. Agrijati. 2(1): 1-7.
Ambarita, Y., D. Hariyono, dan N. Aini. 2018. Aplikasi Pupuk NPK dan Urea Pada Padi (Oryza sativa L.) Sistem Ratun. Jurnal Produksi Tanaman. 5(7): 1228-1234.

BBSDLP. 2011. State of the art and grand design pengembangan lahan rawa. Balai Besar Sumber Daya Lahan Pertanian, Bogor. pp. 44

Bovairi, M., Shokuhfar, A. and Abadouz, G. R. 2016. Effect of Cutting Height and Seed Cutting Date on Grain yield and Yield Components in Berseem Clover (Trifolium alexandrinum L.). Research on Crop Ecophysiology. 11(2): 104-111

Dakhyar, N., A. Hairani, dan L. Indrayati. 2012. Prospek pengembangan penataan lahan sistem surjan di lahan rawa pasang surut. Agrovigor. 5(2):113-118

Duan, Y. H., Y. L. Zhang, L. Y. Ye, X. R. Fan, G. H. $\mathrm{Xu}$, and Q. R. Shen. 2007. Responses of rice cultivars with different nitrogen use efficiency to partial nitrate nutrition. Ann. Bot. 99: 1153-1160

Fifi, M. 2016. Pengaruh Pemberian Pupuk NitrogenTerhadap Pertumbuhan dan Hasil Ratun Tanaman Padi Sawah (Oryza sativa L.) [ diunduh 28 Juli 2019]. Tersedia pada: http://scholar. unand ac.id/id/eprint/19366.

Gribaldi, Suwignyo, R.A., Hasmeda, M. \& Hayati, R. 2013. Pengaturan aplikasi pupuk nitrogen untuk meningkatkan toleransi dan pemulihan tanaman padi terhadap cekaman terendam. Jurnal lahan suboptimal. 2(2): 151-158

Gribaldi, R.A. Suwignyo, M. Hasmeda, and R. Hayati. 2016. Fertilization strategy to increase rice 
growth and production under two flooding condition on two lowland swamp types. Int. J. Agrivita. 38(1):64-72.

Modhej,A., A. Naderi, Y. Emam, A. Aynehband and G. Normohamadi, 2008. Effects of postanthesis heat stress and nitrogen levels on grain yield in wheat (T.durum and T. aestivum) genotypes. Int. J. Plant Production. 2: 257267.

Nakano, H., S. Morita, H. Kitagawa, and M. Takahashi. 2009. Effect of cutting height and trampling over stubbles of the first crop on dry matter yield in twice harvest of forage rice. Plant Prod. Sci. 12:124-127.

Naning. M.I., D.M. Bernas, D. P. Sulistiyawah and S. Nurul, 2008 Proceedings of the annual meeting of the scientific association of Indonesian soil science, Palembang. Desember 17-18, 2008.

Nurmayulis, Utama, P. , Firnia, D., Yani, H dan Citraresmini,A. 2011. Respons Nitrogen dan Azolla terhadap Pertumbuhan Tanaman Padi Varietas Mira I dengan Metode SRI. Jurnal Ilmiah Isotop dan Radiasi . 7(2): 115-125

Setiawan, A., J. Moenandir, dan H. Nugroho. 2012. Pengaruh Pemupukan N,P, K Pada Pertumbuhan dan Hasil Padi (Oriza sativa L.) Kepras. http://pustakapertanianub.staff. ub.ac.id/files/2012/05/JURNAL.pdf. (Diakses 1 April 2015).

Siregar, Adan I. Marzuki. 2011. Efisiensi Pemupukan Urea Terhadap Serapan N dan Peningkatan Produksi Padi Sawah (Oryza sativa L.). Jurnal Budidaya Pertanian. 11(2): 251-261
Sudana, W. 2005. Potensi dan Prospek Lahan Rawa Sebagai Sumber Produksi Pertanian. J. Analisis Kebijakan Pertanian. 3(2): 141151

Susilawati, B.S. Purwoko, H. Aswiddinnor dan E. Santoso. 2010. Keragaan varietas dan galur padi tipe baru Indonesia dalam system ratoon. J. Agron. Indonesia. 38 (3): 177-184.

Triadiati, A. A. Pratama, dan S. Abdulrachman. 2012. Pertumbuhan dan Efisiensi Penggunaan Nitrogen pada Padi (Oryza sativa L.) Dengan Pemberian Pupuk Urea yang Berbeda. Buletin Anatomi dan Fisiologi. Vol. XX(2): 1-14.

Warso. 2014. Pupuk Tanaman Padi Sawah-Panen Maksimal. http://komunitas_bbp.blogspot. com/2014/02/pupuk-untuk-tanaman-padisawah.html (Diakses 2 April 2015) 